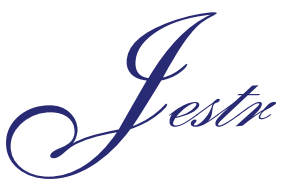

\title{
Intelligence Controller for STATCOM Using Cascaded Multilevel Inverter
}

\author{
P. K. Dhal ${ }^{1}$ and C. C. Asir Rajan ${ }^{2, *}$
}

${ }^{I}$ Department of EEE, Vel Tech Technical University, Avadi, Chennai - 600062 , India.
${ }^{2}$ Department of EEE, Pondicherry Engineering College, Pondicherry - 605 014, India.

Received 10 January 2010; Revised 9 March 2010; Accepted 30 March 2010

\begin{abstract}
This paper presents a special gating pattern swapping technique for cascaded multilevel inverter, which is used for STATCOM. By using this technique besides minimizing the harmonic level, the inverter unit fundamental output voltages are equalized. Therefore, all the inverter units in each phase leg can equally share the exchanged active and reactive power with the utility grid. This greatly helps the dc-link voltages balancing control. PI Control is employed for improving performance. Fuzzy control is employed to the system for enhancing transient stability. The performance is analyzed using digital simulation.
\end{abstract}

Keywords: STATCOM, PWM, Fuzzy Logic, Multilevel inverter.

\section{Introduction}

The rapid growth in electrical energy use, combined with demand for low cost energy, has gradually led to the development of generation sites remotely located from the load center. The generation of bulk power at remote locations necessitates the use of transmission line to connect generation sites to load centers. With long distance ac power transmission and load growth, active control of reactive power is indispensable to stabilize the power system and to maintain the supply voltage. The static synchronous compensator (STATCOM) using voltage source inverters has been accepted as a competitive alternative to the conventional Static VAr compensator (SVC) using thyristor-controlled reactors STATCOM functions as a synchronous voltage source. It can provide reactive power compensation without the dependence on the ac system voltage. By controlling the reactive power, a STATCOM can stabilize the power system, increase the maximum active power flow and regulate the line voltages. Faster response makes STATCOM suitable for continuous power flow control and power system stability improvement. The interaction between the AC system voltage and the inverter-composed voltage provides the control of the STATCOM var output [7] [8]. When these two voltages are synchronized and have the same amplitude, the active and reactive power outputs are zero.

However, if the amplitude of the STATCOM voltage is smaller than that of the system voltage, it produces a current lagging the voltage by $90^{\circ}$ and the compensator behaves as a variable capacitive load. The reactive power depends on the voltage am-

*E-mail address: asir_70@hotmail.com

ISSN: 1791-2377 (C) 2010 Kavala Institute of Technology. All rights reserved. plitude. This amplitude control is done through the control of the voltage on the dc capacitor. This voltage is related to the energy stored at the dc capacitor. By lagging or leading the STATCOM voltage, it is possible to charge or discharge the dc capacitor; as a consequence, change the value of the dc voltage and the STATCOM's operational characteristics and the compensator behaves as an inductive load, which reactive value depends on the voltage amplitude. Making the STATCOM voltage higher than the AC system voltage the current will lead the voltage by $90^{\circ}$. In the past few decades, various STATCOM systems have been put into service. Most of them use transformer-based multipulse inverters [1]. In this topology, multiple six-pulse inverters are magnetically coupled through a complex zigzag transformer. An alternative approach is to use multilevel inverters, which can eliminate the bulky zigzag transformer. To overcome the limitations of semiconductor device, many new techniques are developed [4]-[6]. They are multiple switching elements in one leg of an inverter, series connected inverter, and parallel connected inverters. Among these various multilevel topologies, the cascaded multilevel inverter can implement a high number of levels with ease. The modular structure and the ease of redundant operation are also advantages [2].

In conventional cascaded multilevel inverter use fundamental switching frequency [2] to generate step waveform at low harmonic distortion and keep the switching loss as low as possible. But the inverter units' duty cycles are different from each other. Due to unequal duty cycle the inverter units cannot equally share the exchanged power with the utility grid [3]. In STATCOM to balance [5] the dc-link voltages, additional auxiliary inverters were 
used to exchange the energy among various capacitors. But the disadvantage is high cost and complexity in hardware design. In [2], to eliminate unequal duty cycles, the required dc capacitance of each inverter unit is calculated according to the corresponding duty cycle. But in practical application modular design is very difficult. By using proposed method inverter units' fundamental output voltage are equalized. Consequently, all the inverter units can equally share the exchanged power with the utility grid, and the dc-link voltage balancing control can be simplified. A special gating pattern is used for maintain the dc capacitor charge balance and equalize the current stress of the switching device.

This paper presents the comparisons of fundamental frequency modulation strategy given in section 2 , followed by optimal modulation strategy and comparison between two strategies is given in section 3. Conclusion is given in section 4 .

\section{Fundamental Frequency Modulation Strategy}

Fig. 1 shows the basic structure of cascaded multilevel inverter with separate dc source. For a three phase system, the output voltage of the three cascaded inverters can be connected either star or delta [2].

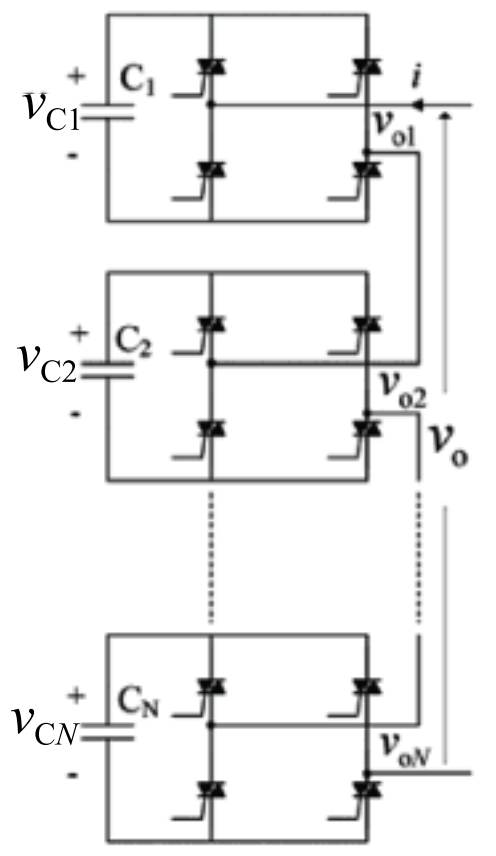

Figure 1. Basic Structure of Cascaded Multilevel Inverter.

\section{Advantages:}

- Requires the least number of components among all multilevel converters to achieve the same number of voltage levels.

- Modularized circuit layout and packaging is possible because each level has the same structure, and there are no extra clamping diodes or voltage balancing capacitors.

- Soft switching can be used in this structure to avoid bulky resistor-capacitor-diode snubbers.

\section{Disadvantages:}

- Needs separate dc sources for real power conversions, and thus its applications are somewhat limited.

\section{Multilevel Optimal Modulation Strategy}

\subsection{Algorithm of the Multilevel Optimal Modulation}

A 100Mvar STATCOM device is connected to the $230-\mathrm{kV}$ (L-L) grid network. Fig.2 shows the single line diagram representing the STATCOM and the host sample grid network. The feeding network is represented by a thevenin equivalent at (bus B1) where the voltage source is represented by a $\mathrm{kV}$ with 10,000 MVA short circuit power level with a followed by the transmission line connected to bus B2. The STATCOM device comprises the voltage source converter-cascade model connected to the host electric grid. 7-level is chosen here for STATCOM. It is connected to the network through the coupling transformer. The dc link voltage is provided by the capacitor $\mathrm{C}$, which is charged from the ac network. The decoupled current control system ensures full dynamic regulation of the bus voltage and the dc link voltage.

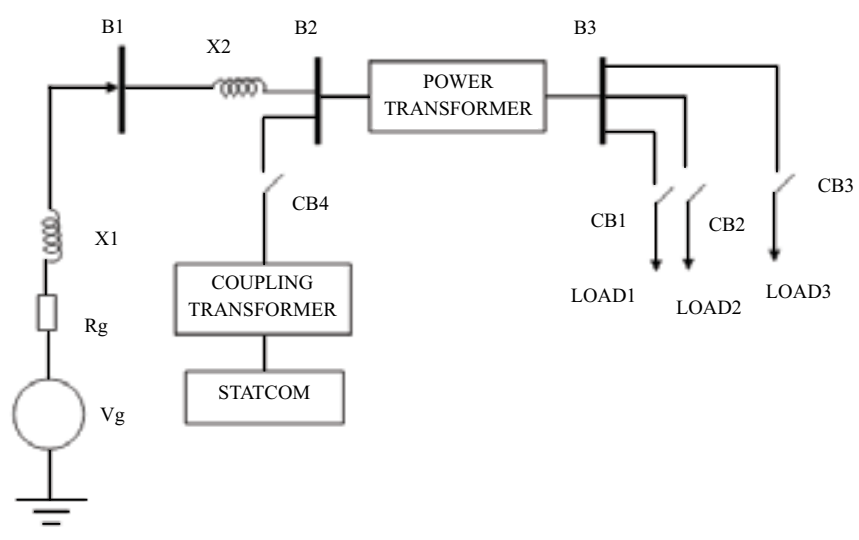

Figure 2. Single Line Diagram Representing STATCOM.

At the time of starting the source voltage is such that the STATCOM is inactive. It neither absorbs nor provides reactive power to the network. The following load sequence is tested and results are taken.

At $\mathrm{t}=0.06$ sec STATCOM is connected to the system by switching circuit breaker CB4.

At $\mathrm{t}=0.1$ load 1 is connected by switching $\mathrm{CB} 1$.

At $\mathrm{t}=0.3$ load 2 is connected by switching CB2.

At $\mathrm{t}=0.5$ load 2 is connected by switching CB3.

Fig. 3 illustrates the typical output voltage waveforms when using the proposed optimal modulation strategy .The square wave is chopped three times per half cycle and the corresponding switching frequency of the IGCTs is $150 \mathrm{~Hz}$. Thethree switching angles of the inverter unit are depicted using. Since the waveform has quarter-wave and half wave symmetry, no even harmonics exist. Normalized with respect to the corresponding dc-link voltage. 


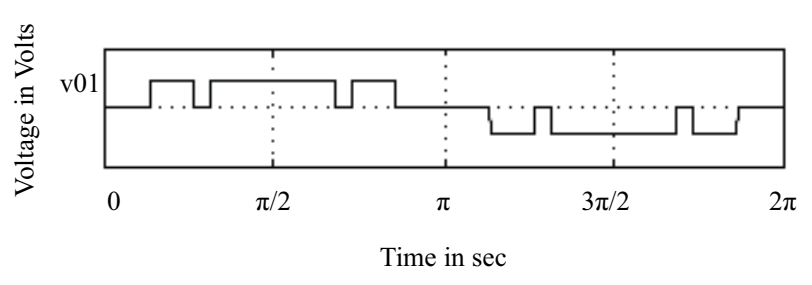

Figure 3. Waveforms of the output voltages of inverter units and their switching angles.

\subsection{Gating Pattern Swapping Among Various Device}

Compared with the fundamental frequency technique, a disadvantage of the $150 \mathrm{~Hz}$ modulation technique is the unequal conduction time of the four switching devices in one inverter unit, as illustrated in Fig. 3. To realize an equal utilization of the switching devices, a special scheme is developed to swap the gating signals among the four switching devices in an inverter unit. As shown in Fig.4, there are two gating patterns for the inverter unit to generate the desired voltage waveform. They are denoted as Pattern-1 and Pattern-2. Swapping these two gating patterns per cycle can equalize the average conduction time of the switching devices and equalize the devices' current stress. However it should be noted that an additional switching action occurs at the swapping time, which brings unexpected increase of switching loss. To minimize this additional switching loss, the gating-pattern is swapped every ten cycles, instead of one cycle. Thus, the increased switching loss brought by gating pattern swapping can be omitted.
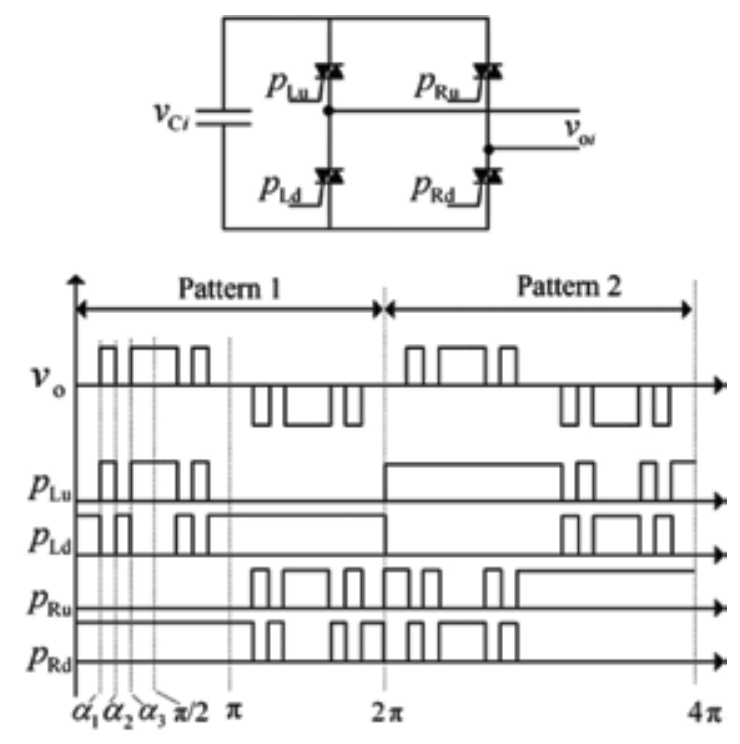

Figure 4. Waveforms of the output voltages of inverter units and their switching angles.

\subsection{Calculation Of Switching Angles}

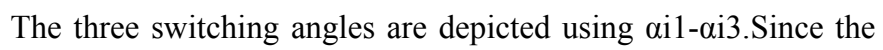
waveform has quarter-wave and half wave symmetry, no even harmonics exist. Normalized with respect to dc voltage, the Fourier coefficient is magnitudes of the output voltage of the $i^{\text {th }}$ inverter unit is given by,

$$
h_{i}(n)=(4 / n \pi) \sum_{k=1}^{3}(-1)^{k+1} \cos \left(n \alpha_{i k}\right)
$$

Where, $\mathrm{n}=1,3,5 \ldots \ldots$

The first optimization objective is to equalize the inverter units' fundamental output voltages.

$$
h_{i}(n)=(4 / n \pi) \sum_{k=1}^{3}(-1)^{k+1} \cos \left(n \alpha_{i k}\right)=M
$$

where,

$\mathrm{i}=1,2 \ldots \mathrm{N}$

$\mathrm{M}=$ Modulation Index

Another optimization objective is the harmonic distortion of the synthesized output voltages. The coefficient magnitude of the nth harmonic of the synthesized phase voltage is given by

$$
h_{i}(n)=(4 / n \pi) \sum_{i=1}^{N} \sum_{k=1}^{3}(-1)^{k+1} \cos \left(n \alpha_{i k}\right)
$$

The minimizing function of the THD is given by

$$
\min F=\sum_{N=3,5,7, . .}^{G} H(n)^{2}
$$

where $\mathrm{G}=2 \mathrm{Nk}-1$

The linear inequality constraint that the minimization should be subjected to is

$0<\alpha \mathrm{i} 1<\alpha \mathrm{i} 2<\alpha \mathrm{i} 3<\pi / 2$

Using equations (2), (4), (5) switching angles can be calculated using mathematical tool such as MATLAB.

\section{Control Scheme For STATCOM}

To regulate the system voltage and reactive power compensation PI control is employed. To enhance the transient stability fuzzy control is employed.

\subsection{PI Control For STATCOM}

Auxiliary control method is used to regulate the system voltage and to regulate the reactive power current effectively. Fig 5 shows the controller for STATCOM. The output of the PLL is the angle that used to measure the direct axis and quadrature axis component of the ac three-phase voltage and current. The outer regulation loop comprising the ac voltage regulator provides the reference current (Iqf) for the current regulator that is always in quadrature with the terminal voltage to control the reactive power. The voltage regulator is a PI controller. A supplementary regulator loop is added us- 
ing the dc capacitor voltage. The dc side capacitor voltage charge is chosen as the rate of the variation of this dc voltage. The current regulator controls the magnitude and phase of the voltage generated by the PWM converter (Vq, Vd) from the Idf and Iqf reference currents produced, respectively, by the dc voltage.

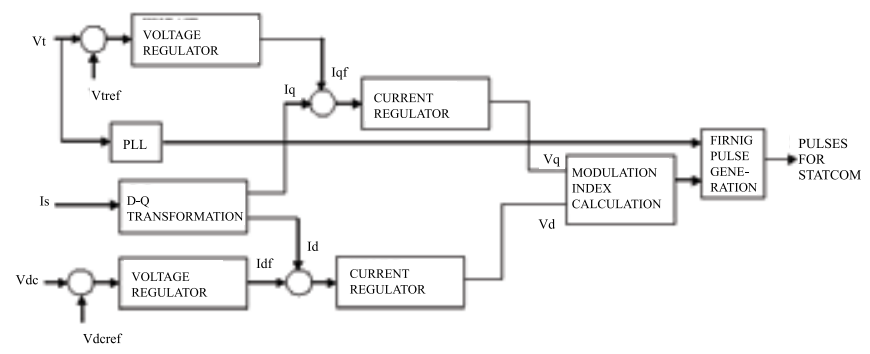

Figure 5. PI Controller for STATCOM.

\subsection{Fuzzy Control For STATCOM}

To enhance the transient stability AC power system fuzzy controller is adopted for the STATCOM system. The fuzzy controller is a nonlinear controller and it is not sensitive to system topology, parameters and operation condition changes. This feature makes very useful for power system applications.

Fig 6 shows the fuzzy logic control system of STATCOM. The presented control system has two control loops [9], [10]. The first control loop is named main controller and control the output voltage magnitude of STATCOM by adjusting modulation index an order to regulating the AC bus voltage. The second control loop is named supplementary controller and controls DC link capacitor voltage by adjusting the phase angle of STATCOM output voltage.

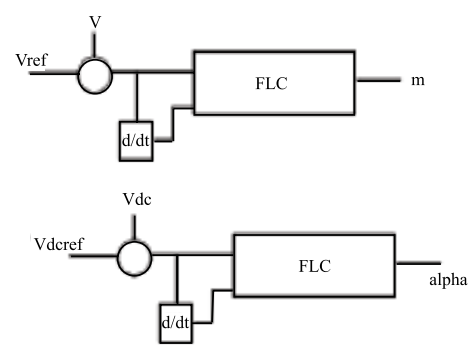

Figure 6. Fuzzy logic control system of STATCOM.

Seven linguistic variables are defining for AC voltage and change in AC voltage, which ranges from -1 to +1 . The input signal foe supplementary control system is similar to AC bus voltage controller functions. Fig 6(a) shows the membership function for signal of AC and DC voltage regulator.

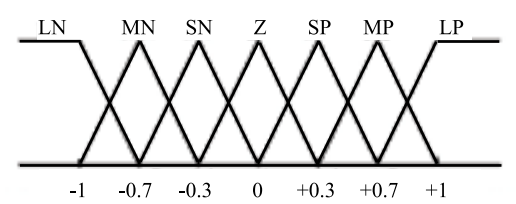

Figure 6a. Membership function for signal of AC and DC voltage regulator.

Fig 7 shows the output voltage at various load conditions without controller and 7(a) shows the real and reactive power of the system at bus 3 without controller. Fig 8 shows the voltage at bus 3 by using PI controller. Fig 8(a) shows the real and reactive power of the system at bus 3 by using PI controller. Fig 9 shows the voltage at bus 3 by using fuzzy controller. Fig 9(a) shows the real and reactive power of the system at bus 3 by using fuzzy controller. From the graph it is inferred that transient period is reduced and also voltage is regulated. Reactive power is reduced and active power is improved.

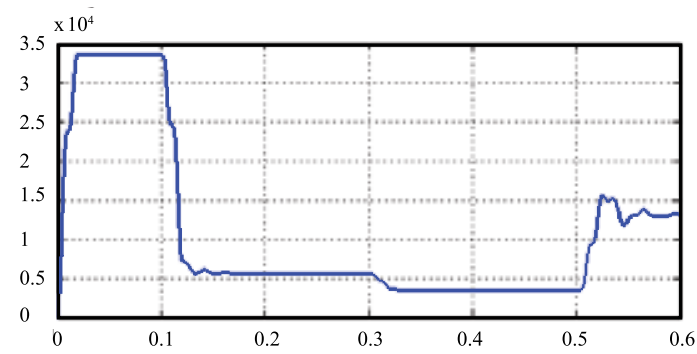

Figure 7. Output Voltage Waveform at Bus 3 without controller.

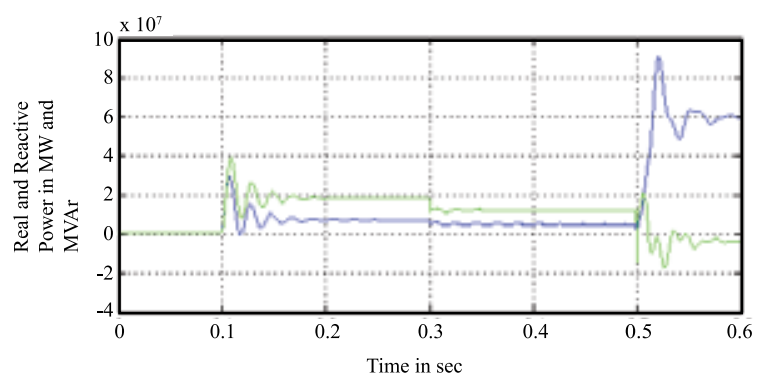

Figure 7(a). Real and Reactive at Bus 3 without controller.

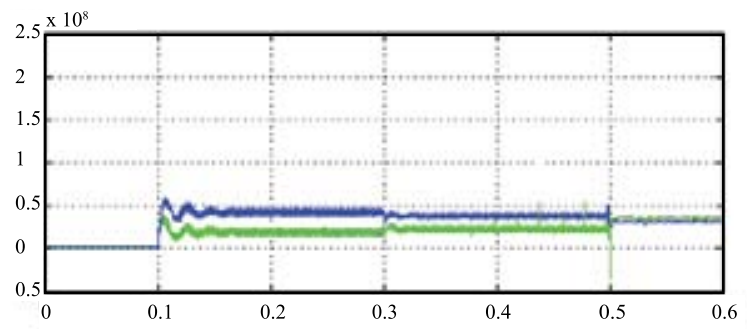

Figure 8. Real and Reactive power at bus 3 using PI.

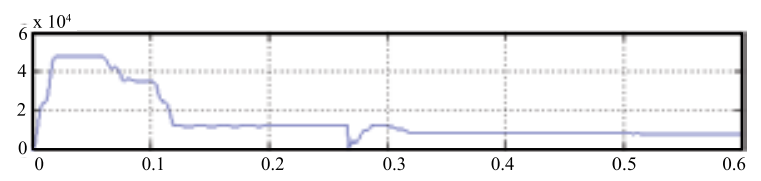

Figure 8(a). Output Voltage Waveform at Bus 3 using PI.

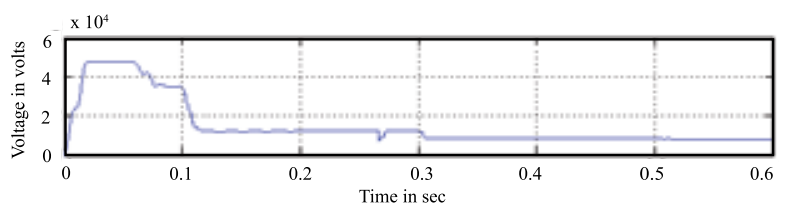

Figure 9. Output Voltage waveform at Bus 3 with fuzzy control.

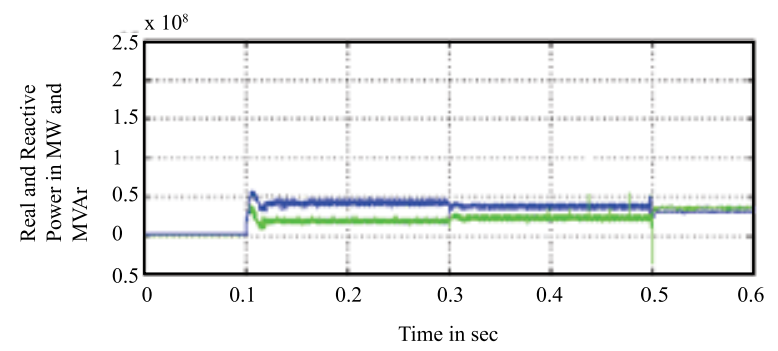

Figure 9(a). Real and Reactive Power at Bus 3 with fuzzy Control. 


\section{Conclusion}

A 100Mvar STATCOM device is connected to the $230-\mathrm{kV}$ (LL) grid network. For switching the device, swapping technique is adopted. The scheme of gating-pattern swapping among the various devices can equalize device current stresses. A multilevel optimal modulation strategy was proposed for STATCOM, is incorporated in system line. So the system is easily balanced. PI control is employed for the better performance. Fuzzy Control is employed to enhance the transient stability. Voltage and real and reactive power waveform at bus 3 under open loop and using PI controller and fuzzy is discussed. It is inferred from the graph that real power improved using PI controller and transient is reduced using fuzzy control. Further, the work can be done by using neurofuzzy control.

\section{Appendix}

\section{For STATCOM}

Rated Power $=100 \mathrm{MVAr}$

Rated voltage $=138 \mathrm{kV}$

Interface inductor $(\mathrm{L})=2.86 \mathrm{mH}$

Resistance $(\mathrm{Rs})=0.0898 \Omega$

\section{For grid}

Rated Voltage: $230 \mathrm{kV}$

Short Circuit Capacity: 10000 MVA

For Power Transformer (Y/Y)

Rated Voltage $220 \mathrm{kV} / 33 \mathrm{kV}$

Rated Power: 300 MVA

For Coupling Transformer (Y/Y)

Rated Voltage 138 kV/230 kV

Rated Power: 100 MVA

Three Phase Load

Load 1:

$\mathrm{P}=100 \mathrm{MW}$

$\mathrm{Q}=80 \mathrm{MVAr}$

Load 2:

$\mathrm{P}=70 \mathrm{MW}$

$\mathrm{Q}=50 \mathrm{MVAr}$

Load 3:

$\mathrm{P}=60 \mathrm{MW}$

$\mathrm{Q}=40 \mathrm{MVAr}$

\section{References}

1. N. G. Hingorani and L. Gyugyi, Understanding FACTS, Concepts and Technology of Flexible AC Transmission Systems, Piscataway, NJ: IEEE Press (2000).

2. F. Z. Peng, J. S. Lai, J. W. McKeever and J. VanCoevering, IEEE Trans. Ind. Appl., 32, 1130 (1996).

3. P. K. Steimer, H. E. Gruning, J.Werninger, E. Carroll, S. Klaka and S. Linder, IEEE Ind. Appl. Mag., 5, 12 (1999).

4. P. M. Bhagwat and V. R. Stefanovic, IEEE Trans. Ind. Applicat., 19, 1057 (1983).
5. M. Marchesoni and M. Mazzucchelli, Proc. IEEE Int. Symp. Industrial Electronics, 38-43, 1993.

6. G. Carrara, S. Gardella, M. Marchesoni, R. Salutari and G. Sciutto, IEEE Trans. Power Electronics, 7, 497 (1992).

7. S. Mori, et al., IEEE Trans. Power Delivery, 8, 371(1993)

8. N. Seki and H. Uchino, IEEE Trans. on Industry Applications, 33 (1997)

9. S. A. Al-Mawsawi, IETECH Journal of Electrical Analysis, 1, 104 (2007).

10. A. Ajami and S. H. Hosseini, Proc. Intl. Joint Conf. ICASE, 6059-6063, 2002. 